\title{
GÊNERO E COMPORTAMENTO: CASOS DE SEDUÇÃO NA CIDADE DE LONDRINA (1960-1970) ${ }^{19}$
}

Tamara Vieira ${ }^{20}$

Célia Regina da Silveira ${ }^{21}$

Resumo: Esta pesquisa procura investigar as relações entre o comportamento feminino de jovens mulheres pertencentes às classes populares e o processo de disciplinarização social formulado pelas autoridades jurídicas. Queremos compreender como tais fatores influenciavam as práticas cotidianas que as jovens estabeleciam na sociedade, em especial no namoro e casamento. Nossas fontes primárias para esta pesquisa são os autos criminais de sedução da cidade de Londrina, entre os anos de 1960 e 1970, e a coluna Feminilidades do jornal Folha de Londrina, escrita por Tia Jurema.

Palavras-chave: Gênero. Discurso jurídico. Sedução. Tia Jurema.

Para a produção deste trabalho foi usado como fonte os autos criminais da Comarca de Londrina (1939-1970) ${ }^{22}$, que possuem como tema crimes sexuais contra a mulher: o estupro (art. 213); atentado violento ao pudor (art. 214); sedução (art. 217) e o crime de defloramento ${ }^{23}$. Ao longo da pesquisa foi lida uma bibliografia sobre a História do município, para percebermos como ele foi se construindo e as personagens que contribuíram para seu crescimento, também sobre "a história vista de baixo", campo da história que vem mostrar o olhar do homem comum sobre a História e que este também participa e faz História.

É este sujeito esquecido e silenciado que lhes apresento, a mulher pobre londrinense, mais especificamente as vítimas dos crimes de sedução, na tentativa de compreender seu papel de mulher na cidade de Londrina e como elas eram vistas nos discursos jurídicos, além de sua tentativa de se encaixar em um perfil feminino determinado pela sociedade. Os autos cobrem o período de 1939 e 1970, neste trabalho optou-se por um recorte temporal, que privilegiará as décadas de 1960 e 1970.

A mulher como o homem tinha um papel na sociedade e um espaço delimitado a ela. Vejamos:

19 Este trabalho é resultado da pesquisa vinculada ao projeto "Sedução, infância e violência: um estudo sobre as relações familiares e gênero na cidade de Londrina (1939-1970), no período de agosto de 2006 a outubro de 2008.

20 No período de elaboração desta pesquisa a aluna era bolsista do Programa de Ações Afirmativas a Inclusão Social da Universidade Estadual de Londrina (UEL).

21 Orientadora, professora doutora do Departamento de História da UEL.

22 Encontram-se no Centro de Documentação e Pesquisa Histórica da Universidade Estadual de Londrina

(CDPH-UEL).

23 No que diz respeito ao crime de defloramento não foi encontrado artigo, pois defloramento é a perda da virgindade em si, algo que ocorre no caso de estupro e podendo ocorrer nos casos de sedução, onde os envolvidos poderiam praticar relação sexual. Mas, nas décadas abrangidas por esta pesquisa foram registrados como motivo do processo o defloramento, ao longo do processo seria definido a ação que ocasionou a perda da virgindade da moça, assim 0 artigo em que se enquadra o crime. 
[...] à mulher coube a ocupação do espaço doméstico e ao homem o espaço público, sedimentando uma relação de desigualdades entre os gêneros, ou seja, entre homens e mulheres [...] a esfera pública é o espaço para convivio dos iguais, enquanto a esfera privada é destinada à manifestação e preservação das desigualdades [...] a mulher foi excluída da esfera pública e oprimida na esfera privada [...] (Secretaria da Mulher de Londrina, 2000, p. 15).

A mulher pobre londrinense não se restringiu ao espaço privado e se incluiu no espaço público, sua situação a obrigou a buscar trabalho, tarefa que se restringia ao papel do homem na sociedade. Mas elas não foram às primeiras mulheres da história a trabalharem por causa da situação financeira em que se encontravam.

O gênero analisado neste trabalho refere-se ao comportamento de um homem que o define como tal e de uma mulher que a define como mulher, ou seja, masculino e feminino: estados que são construídos através dos tempos e das relações humanas, que não são definidos exclusivamente pelo fator biológico, não se tratando dos órgãos sexuais como definidores únicos dos padrões comportamentais de um homem e uma mulher.

No período analisado era obrigação do homem prover sua família, mas quando esse não tinha condições para atingir tal objetivo, sua esposa, filhos ou mesmo filhas trabalhavam ajudando para o aumento da renda da casa.

A mulher presente nos autos criminais de Londrina nas décadas de 1960 e 1970 se encontrava em vários espaços que a afastava do perfil feminino aceito como correto pelas normas sociais, o de se restringirem ao âmbito do privado. Ao trabalhar a mulher pobre se colocou a margem da lei social e do Estado, mas como toda mulher sonhava com a constituição de uma família e em praticar a maternidade.

Elas se viam obrigadas a saírem sozinhas e a trabalhar, como conseqüência tinham relações com um maior público, dentre esse, incluíam-se os homens. Nos discursos jurídicos presentes nos autos-criminais, nota-se um perfil feminino que a lei deveria proteger contra os crimes de estupro, atentado violento ao pudor, sedução e o crime de defloramento, estas deveriam apresentar certos comportamentos, por exemplo, "instinto materno, pureza, resignação e doçura" (DEL PRIORE, 1997, p. 608), além de se ocuparem dos afazeres domésticos "e o cuidado dos filhos" (DEL PRIORE, 1997, p. 608), esta mulher era "treinada" desde criança sobre os comportamentos adequados à uma mulher.

O fato de uma mulher ser vítima de estupro, atentado violento ao pudor, sedução e defloramento, acabaria com sua reputação e a chance de se casarem. Se a moça pertencia a uma família com posses o criminoso poderia ser obrigado a se casar com a vítima ou se procurava um terceiro para que o mal fosse reparado, o mais rápido possível. Ao passo que as moças pertencentes a famílias pobres recorriam à justiça em busca da punição, o processo era longo e as colocavam em uma situação em que suas vidas eram devassadas, e não tinham certeza da sentença.

Nestes casos não eram apenas as vítimas as desonradas, também suas famílias em relação à 
educação que deixaram de dar a moça. Recorriam à justiça para se restaurar a honra perdida com a sentença a favor ou com o casamento.

Em um processo penal não se julga o crime isoladamente, mas sobretudo, os indivíduos envolvidos no caso (vítima e réu), ou seja, as atitudes dos sujeitos que acarretaram ao crime, como explica Aradillon e Debert:

- que se tenta fazer, é enquadrar homens e mulheres concretos dentro de padrões idealizados, e comprovar a sua maior ou menor adequação a eles. Do sucesso dessa operação é que vai depender a condenação ou absolvição dos acusados, pois o que se pune é a conduta social do acusado e da vítima, e não o crime cometido (1987, p.7, grifos meus).

O crime de sedução encontrado no Código Penal Brasileiro (1940) é regido pelo artigo 217, como sendo:

Seduzir mulher virgem, menor de dezoito anos e maior de quatorze, e ter com ela conjunção carnal, aproveitando-se de sua inexperiência ou justificável confiança.

Pena - reclusão, de dois a quatro anos.

Era vítima do crime de sedução a mulher menor de dezoito anos e maior de quatorze, ao ser menor de quatorze anos o crime seria de corrupção de menores e a moça sendo maior de dezoito anos não se encontrava mais sobre a proteção da justiça. Como a idade era um dado que caracterizava o crime, era necessário anexar a certidão de nascimento da vítima ao processo. A perda da virgindade era constatada com o Laudo de Conjunção Carnal, era feito um exame ginecológico na moça que verificava a perda recente ou não da virgindade, também se a vítima apresentava hematomas ou algum problema ocasionado pela relação sexual, o Laudo era também anexado ao processo.

A próxima questão apresentada pelo artigo trata da "inexperiência ou justificável confiança" que a menor apresentava em relação ao sedutor. Neste item do artigo o comportamento da jovem é questionado. Era o momento em que se cobrava o comportamento adequado à mulher, ou seja, o comportamento aceito pela sociedade para as mulheres, como sua inexperiência em relação ao "mal" da sociedade, em especial no que diz respeito ao seu desconhecimento sobre relações sexuais e sua total confiança nas promessas de um homem.

Ao sentenciar um processo de sedução datado com inicio em 16/11/1970 e terminado em 27/02/1974 o juiz Dr. Alfredo José Rattmann apresenta os elementos que caracterizam o crime de sedução. Trataremos mais especificamente a questão da inexperiência e da justificável confiança.

O termo usado pelo Código Inexperiência, não que dizer ingenuidade, inocência completa.... a donzela inexperiente é "aquela que não pode avaliar em toda sua extensão as conseqüências de seu ato, por menos trato das coisas da vida, por ignorante das maldades do mundo, por não apercebidas das ciladas do homem".

A justificável confiança, "resultará do noivado oficial, da promessa de casamento, 
do namoro indissimulado, das freqüentes e significativas visitas do agente à casa da ofendida".

O dolo [...] consiste no propósito do agente de manter conjunção carnal com a donzela de 14 a 18 anos, sabendo que ela se entrega por inexperiência ou justificável confiança. ${ }^{24}$

O processo de sedução era iniciado com a queixa, feita pelos pais ou responsável da menor, em "seguida tomavam-se as primeiras providências, como depoimentos, laudo de conjunção carnal, rastreamento da vida pregressa do acusado, dados pessoais de ambos, e finalizava-se com um relatório do caso, emitido pelo delegado" (RIBEIRO, 1996, p. 33). Além dos principais personagens do caso eram arroladas outras pessoas no processo como testemunhas, para se poder formar um perfil dos envolvidos, estes tinham "seu cotidiano vigiados, suas ações desvendadas e interpretadas. Essa invasão causa maior dano quando a parte envolvida pertence à categoria feminina" (RIBEIRO, 1996, p.34). Ao finalizar a primeira parte o delegado policial encaminhava o relatório ao cartório criminal, onde as testemunhas prestavam outro depoimento com o objetivo de comparar os depoimentos anteriores com os atuais, esta demora do processo tinha como objetivo a possibilidade do caso se resolver entre os envolvidos.

Observa-se em um processo de sedução a tentativa dos envolvidos em se enquadrarem ou não "dentro de padrões idealizados" como normais pela sociedade. O processo que será analisado é da década de $1970^{25}$, os sujeitos namoravam há dois anos, Maria na época da queixa tinha 16 anos e Júnior 19 anos, a moça morava com seu tio em Londrina, o pai se encontrava falecido e sua mãe residia em São Paulo em local desconhecido, a moça possuía educação primária e trabalhava como doméstica. Já o rapaz era natural da cidade de Londrina também possuía educação primária e trabalhava como sacador de uma fábrica de rações.

Durante o tempo de namoro Júnior freqüentava a casa de Maria assiduamente, planejavam se casar em aproximadamente três meses, mas não havia um pedido formal de casamento, ou seja, o casamento fora algo discutido apenas entre os dois. Em um pásseio "na noite de 30 de setembro de 1970 por volta das 22 horas, num campo de futebol localizado no jardim Leonor, nesta cidade, o acusado conseguiu seduzir a vitima, mantendo com a mesma pela primeira vez conjunção carnal" 26 que aconteceu outras vezes, logo desapareceu abandonando a moça.

A queixa foi feita quando, após manterem relações sexuais vezes a moça percebeu que Júnior havia desaparecido, eles não se encontravam mais e ela não sabia de seu paradeiro, o namorado havia abandonado-a. Foi quando falou com seu tio sobre a promessa de casamento e a perda da virgindade, e o responsável pela menor fez a queixa. Em juízo o réu diz que se casaria com Maria, pois tinha noção do mal que o fato de não ser mais virgem faria a moça, entretanto desfaz o pedido pelo fato da jovem não manter um comportamento correto para uma mulher, e não possuir condições 
para com ela se formar uma família. Fala passível de ser vista no discurso do advogado de defesa, Dr. João Victor dos Santos Couto, defesa prévia:

[...] concluimos que o mesmo, apesar de sua pouca idade, tinha boas intenções com referencia a vitima [...] teve relações sexuais com a vitima, não podemos afirmar se a deflorou, os proprios médicos não puderam precisar, por ser a mesma portadora do ímem complacente, e não encontraram indícios de defloramento.

O importante é [...] provar em juiso, a razão pela qual levou o mesmo a não se casar depois de preparar os papeis... [a vitima] não tem conduta de mulher que possa construir, um lar, si a mesma, enquanto o seu futuro marido providenciava os papéis para o casamento, procurava a vida fácil, altas madrugadas, companhias indesejaveis e procedimento indesejavel $[\ldots] .{ }^{27}(\mathrm{sic})$.

Num primeiro momento temos o papel de Maria como à vítima de um sedutor, ao longo do processo os papéis se invertem e a jovem não é apresentada mais como inexperiente, aqui nós vemos a tentativa do advogado de tirar qualquer culpa do réu, apresentando Júnior como arrependido de seus erros e ciente do mal que cometeu. $O$ defensor apresenta um rapaz com atitudes de homem, que "apesar de sua pouca idade, tinha boas intenções com referencia a vitima" ${ }^{28}$ tomando consciência de seus erros tenta remediá-los enquanto Maria se comporta como a mais "vil das mulheres". Discurso que se encontra presente na fala do outro advogado que representa o réu, o Dr. Fernando Moreira de Moraes.

[...] O fato de alguém manter relações sexuais com uma mulher entre 14 e 18 anos não quer dizer que tenha cometido crime previsto no art. 217 do C. P.

Não há qualquer prova de que tenha o réu usado de algum artifício para quebrar a resistência da queixosa [...].

Sedução Excelência, nada mais é do que a posse sexual mediante fraude; esta não pode ser reconhecida.

A ofendida encarrega-se de desfazer possiveis dúvidas: “a primeira relação mantida entre o réu e a vítima (note-se bem: a primeira entre ambos) foi efetivada num matagal; atualmente continuam a manter relações em lugar deserto".

Ora, não é, evidentemente, este tipo de recato, de honestidade que a lei visa proteger. Ao primeiro passo vai para um campo de futebol e se entrega. A vítima é tão "honesta" e cheia de pureza que continua indo para o meio do mato manter relações sexuais. ${ }^{29}$ (grifos meus).

O advogado tenta confrontar o comportamento de Maria com a conduta que se encontra descrita no artigo 217 do Código Penal, na tentativa de provar que a jovem não se enquadrava no perfil que a justiça visa proteger. Como já foi dito o processo é mais doloroso para a mulher, pois é seu comportamento, principalmente o sexual que está em julgamento, é ela que deve ser enquadrada como inexperiente e apresentar justificável confiança em relação ao sedutor.

A tentativa do advogado de defesa está em provar que Maria não se enquadrava neste item do artigo, se baseando no fato de a vítima continuar praticando sexo com o seu namorado. Não 
esqueçamos o local da prática, pois uma mulher dita honesta praticaria sexo apenas com seu cônjuge não menos que este, ou que mulher inexperiente praticaria relação sexual em um local deserto ou mesmo em meio ao mato?

Maria mesmo apresentando hímen complacente ${ }^{30}$ que impossibilitava a confirmação da perda da virgindade, possuía todos os outros itens que a enquadravam em um caso de sedução fazendo com que a sentença lhe fosse favorável, o réu foi condenado pelo crime de sedução e a cumprir três anos de reclusão, mas por ser menor de 21 anos e réu primário cumpriria dois anos da pena. Mas a sentença não foi toda cumprida porque o réu e vítima se casaram no dia 02/01/1974.

O especial neste caso foi o fato da vítima possuir um emprego e este não interferir na sentença, pois a casos em que a moça pelo fato de trabalhar não era considerada inexperiente, portanto, não possuía uma das características principais que caracterizaria o crime de sedução, a inocência que a faria incorrer na "inexperiência ou justificável confiança” em relação ao homem.

No discurso do advogado podemos perceber o que deve ser considerado uma mulher com a qual um homem pode construir um lar, em outras palavras, o comportamento que a mulher não deveria possuir, como por exemplo, a "vida fácil, [andar nas] altas madrugadas, [possuir] companhias indesejáveis e [manter] procedimento indesejável" ${ }^{31}$ ou mesmo com companhias consideradas ruins, pode-se concluir que as companhias de uma mulher dizem muito sobre ela.

O perfil adequado para a mulher não foi compativel com a realidade da grande maioria das mulheres desta cidade, o papel não se enquadrou na realidade vivida por elas, entretanto elas sonhavam com a constituição de um lar, desempenhando assim parte de seu papel feminino. Não é possível saber através dos depoimentos presentes no auto se Maria possuía uma "vida fácil", mas nos autos consta que ela trabalhava de doméstica, podendo assim voltar para casa de noite, provavelmente conhecendo um grande número de pessoas que podiam ter ou não uma moral duvidosa, porém não é o que nos interessa, o importante é perceber que ela tinha inculcado o que era considerado o comportamento correto de uma mulher, o seu papel e suas funções, mas o espaço desta jovem era maior do que o espaço da mulher ideal, pela questão do trabalho fora de casa.

Na coluna Feminilidades escrita pela Tia Jurema ${ }^{32}$, no jornal Folha de Londrina, a colunista descreve qual seria o comportamento correto de uma mulher, elas deveriam ser:

femininas, pacientes, tolerantes, indulgentes, sempre prontas a esquecer e perdoar, sempre dispostas a abrir mão de seus interesses todas as vezes que os interesses do lar, do marido e dos filhos exigirem tal renuncia (Folha de Londrina, 17/03/1960, p.05).

30

31

32 as mulheres deveriam seguir e incorporar, tidos como corretos para as mulheres. Apresentava receitas para os dias de festas, cuidados com a casa e a família, ações que se deveria tomar em determinados momentos, o vestuário correto para determinados momentos, entre outros. A coluna era escrita pelo jornalista Oswaldo Militão que usava o pseudônimo de Tia Jurema. 
A mulher deve ter todas as suas atenções e cuidados com o lar, viver em função dele e não tendo mais nada em mente, saber de tudo e em alguns momentos não saber, atenções que não podem ser mantidas quando se trabalha fora. A questão do trabalho é apresentado em outro artigo da mesma coluna do dia 20/07/1960 que trata sobre as perdas do trabalho feminino para o lar, vejamos:

\begin{abstract}
Com base nas mais recentes estatísticas, cientistas alemães calcularam que as donas de casa que dedicam todo o tempo à direção e manutenção dos lares economizam vinte por cento mais, em relação a mulher que é obrigada a trabalhar fora e não pode, por isso, cuidar da casa o tempo todo.

[...] Os cientistas alemães chegaram à conclusão de que a dona de casa que trabalha no lar ganha pelas economias que faz e não desperdiça como as mulheres que trabalham fora (Folha de Londrina, 30/07/1960, p.05). (grifos meus).
\end{abstract}

É usado pesquisas científicas para dar maior credibilidade ao artigo, principalmente apresentando uma pesquisa feita em outro país, mostrando o quão importante é a permanência da mulher dentro de sua casa, como o marido economizaria se sua esposa não necessitasse trabalhar. Mas as mulheres analisadas nessa pesquisa foram obrigadas pelas circunstancias a trabalhar fora e conseqüentemente diminuir o tempo dado a família, como já foi dito o trabalho destas mulheres se torna muito importante para a manutenção do lar, mesmo não se enquadrándo em todos os requisitos necessários para se enquadrarem no perfil de mulher ideal, a condição social não as impediu de querer formar uma família.

O que se percebe ao ler os autos é a vontade das mulheres de contrair matrimônio, em especial nos processos de sedução, onde as moças apresentam a queixa quando percebem que os sedutores não cumprirão com a promessa de casamento e a justiça se apresenta como a única capaz de resolver tal questão. Se não há a possibilidade de casamento com o acusado ou um terceiro a chance restante é a condenação do réu provando a inocência da jovem no caso, permitindo-Ihe um futuro casamento.

Estas mulheres mesmo não pertencendo à camada abastada da sociedade londrinense, em seu meio tentavam se enquadrar no perfil feminino veiculado através de jornais e revistas. Nas décadas de 60 e 70 do século passado a televisão e o cinema eram vistos como péssimas influências para as jovens. As mulheres que não mantinham o comportamento considerado correto pela sociedade se encontravam a margem da lei social e do Estado, lugar social que as vítimas podiam se encontrar quando a sentença do processo era favorável ao réu, fato que acontecia muitas vezes, como se pode ver na tabela ${ }^{33}$ abaixo:

\begin{tabular}{|c|c|c|}
\hline SENTENÇAS & 1960 & 1970 \\
\hline Arquivado & 74 & 05 \\
\hline Condenado & 22 & 02 \\
\hline Absolvido & 46 & 09 \\
\hline Improcedente & 00 & 02 \\
\hline Casamento ${ }^{1}$ & 06 & 01 \\
\hline Sem Dados & 29 & 01 \\
\hline TOTAL & 171 & 20 \\
\hline
\end{tabular}

33 Sentenças de todos os casos de estupro, atentado violento ao pudor, sedução e defloramento ocorridos nas décadas de 1960 e 1970 na cidade de Londrina. 
Através da tabela podemos ver que as sentenças dos processos em sua maioria acabavam a favor do réu, as vítimas não conseguiam readquirir sua honra. Pode ser constatado também o fato de a grande maioria dos casos em 1960 terem sido arquivados, onde se pode constatar que os processos não foram concluídos, pode-se aventar como causa o casamento das jovens com terceiros, ou a fuga do acusado, também com novas promessas de casamento com o réu a jovem retira a queixa possibilitando a fuga do réu, ou mesmo morte dos sujeitos envolvidos no processo, entre outros. Mas na década de 1970 a maioria das sentenças foi a absolvição dos réus, o que nos permite concluir que as moças não se enquadraram no perfil comportamental feminino veiculado como correto pela sociedade. A questão que se coloca nesta década é se os movimentos feministas ocorridos no mundo e iniciado no país exerceram poder sobre as mulheres da cidade, principalmente sobre as mulheres da classe pobre da cidade de Londrina.

Nesta tabela o que mais chama atenção é o total dos processos em cada década, em especial a queda ocorrida entre as décadas, pois em 1960 são cento e setenta e um casos e em 1970 são apenas vinte casos. Será que a queda tem a ver com o movimento feminista? A absolvição dos réus foi alta nas duas décadas, diferente dos casamentos e das condenações que ocorreram, mas não em números significativos, o processo era longo e não apresentava garantias da prova da inocência da vítima ao término do processo. As moças arriscavam recorrendo a justiça, mas esta era a única forma de restaurarem sua honra, conseqüentemente podendo reconquistar a chance de um casamento.

\section{FONTES}

\section{Autos}

Auto Criminal no. 208/70, pacote $\mathrm{n}$ ․ 113, 1 Vara, data do processo $16 / 12 / 1970-27 / 02 / 1974$ [sedução].

\section{Jornais}

Tia Jurema. Feminilidades: Igualdade de Direito e o Respeito à Mulher. Folha de Londrina, Londrina, 17/03/1960, p.05.

Tia Jurema, Folha de Londrina, Londrina, 30/07/1960, p.05.

\section{REFERÊNCIAS BIBLIOGRAFICAS}

ADUM, SÔNIA M. S. Imagens do Progresso: civilização e barbárie em Londrina (1930-1960). Assis SP. Ed. UNESP: 1991, mestrado. 
ARADILLON, Danielle. DEBERT, Guita Grim. Quando a vítima é mulher: Análise de julgamentos de crimes de estupro, espancamento e homicídio. Brasília: Ministério da Justiça, 1987.

BANN, Stephen. Introdução: As invenções da História In:As invenções da História: ensaios sobre as representações do passado. São Paulo: UNESP, 1994.

BURKE, Peter (org.). História das Mulheres; A História Vista de Baixo. In: A escrita da História: novas perspectivas. São Paulo: Ed. UNESP, 1992.

DEL PRIORE, Mary (org.). História das mulheres no Brasil. São Paulo: Contexto, 1997

DELMANTO,Celso. Código Penal Comentado. Rio de Janeiro: Renovar, 2002.

HOBSBAWN, Eric. RANGER, Terence (orgs.). Introdução: A Invenção das Tradições. In: A invenção das Tradições. Rio de Janeiro: Paz e Terra, 1984.

LONDRINA, Secretaria da Mulher. Mulheres de Londrina: lutas sociais e políticas de 1970 a 2000. Londrina: Secretaria da Mulher, 2000.

NETO, José Miguel Arias. O ELDORADO: Representações da Política em Londrina - 1930/1975. Londrina: Eduel, 1997.

REVEL,Jacques (org.). Construir o "macro" pelo "micro": Fredrik Barth e a "microstoria". In: Jogo das escritas: a experiência da microanalise. Rio de Janeiro: Fundação Getúlio Vargas, 1998.

RIBEIRO, Edméia Aparecida. Meninas ingênuas: uma espécie em extinção? A sexualidade feminina: em práticas e representações - Maringá 1950-1980. UNESP, 1996 (mestrado). 